\title{
Early Use of Electroconvulsive Therapy in Individuals with First Episode Psychosis: A Case Series
}

\author{
Antra Chandan ${ }^{1}$, Vijaya Raghavan ${ }^{1}$ \\ 1- Schizophrenia Research Foundation, R/7A, North Main Road, Anna Nagar West \\ Extension, Chennai, Tamil Nadu 600101, India
}

*Corresponding author: Vijaya Raghavan; Schizophrenia Research Foundation, R/7A, North Main Road, Anna Nagar West Extension, Chennai, Tamil Nadu 600101, India; vijayaraghavan@scarfindia.org

Running title: ECT in first episode psychosis

\begin{abstract}
:
The use of electroconvulsive therapy (ECT) in various neuropsychiatric disorders has been well accepted. ECT has been proven to be safe and effective in adolescents and in old age. However, only a handful of literature is available on its effectiveness in first episode psychosis (FEP). In this case series, individuals with FEP who received ECT in the $1^{\text {st }}$ month of their treatment itself for various indications are described. During follow-up, subjects showed considerable improvement in their psychopathology and functional outcomes. None of them had any adverse events during or after ECT sessions. Thus, the present case series highlights the usefulness and safety of early use of ECT in individuals with first episode psychosis and its effectiveness in reducing the acute symptoms leading to remission and better outcomes.
\end{abstract}

Keywords: electroconvulsive therapy, first episode psychosis, case series 


\section{Introduction:}

According to an operational definition, an individual who presents at a clinical setting with psychosis and who has never previously presented at a clinical setting with psychosis is identified as experiencing their 'firstepisode'. ${ }^{1-5}$ Most of the individuals with FEP are adolescents or young adults in the age group of 15-24 years. ${ }^{6,7}$ Various studies have shown that pharmacological intervention with second generation antipsychotics such as risperidone or

olanzapine along with psychosocial interventions have a good response

rate with nearly $80 \%$ of the individuals attaining pre-morbid status within 6 months of treatment. ${ }^{8,9}$ But there is a definitive sub-group of individuals with FEP who require additional interventions early in the course of the illness. ${ }^{10,11}$

The role of electroconvulsive therapy (ECT) in severe, treatment-resistant chronic schizophrenia is well established. ECT has been used for the treatment of various conditions associated with schizophrenia such as catatonia, acute suicidal ideations, aggressive state/violent behavior and treatment resistance to pharmacological interventions. ${ }^{12,13}$ The effectiveness of ECT and safety is

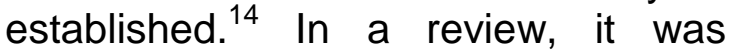
concluded that the combination of antipsychotic medications and ECT is safe and effective for treatment resistant schizophrenia. ${ }^{15}$ Moreover, ECT has been shown to have same effectiveness in adolescents as in adults. ${ }^{16}$

Literature that has explored the role of ECT in first-episode psychosis are few and most of these are from other parts of the world. ${ }^{17,18}$ It is important to understand the usefulness and safety of ECT for FEP in India. Hence, in this current case series, we describe individuals with first episode psychosis who received ECT within the first month of treatment for various indications, changes in their psychopathology during follow-up and adverse effects during and post ECT sessions.

\section{Case 1}

A 28 year old, married female, educated upto $12^{\text {th }}$ grade, from low socio economic status, having two children, with last child birth three months prior to onset by lower section caesarean section (LSCS) and no family history of psychiatric illness presented to the psychiatry OPD with complaints of crying spells, excessive guilt, talking excessively and irrelevantly, hearing voices, suspiciousness, and poor self-care for a period of four weeks.

On clinical examination, the patient was observed to be unkempt, anxious and exhibited restless behavior. She had delusions of reference that people were talking about her, somatic delusions that her body had a fungal infection, nihilistic delusion that all were dead including her baby and auditory hallucinations telling her that she was still pregnant. The client had feelings of guilt that she was infected and that she had broken her baby's hands. She was acutely suicidal. The client was diagnosed with postpartum psychosis.

The client was started on Olanzapine 5 $\mathrm{mg}$ and Clonazepam $2 \mathrm{mg}$ and immediately referred for ECT as she was suicidal. She was administered modified bilateral ECT. A total of 6 ECT sessions were administered. The 
client showed significant improvement after her course of ECT sessions. Her suicidal ideations were drastically reduced by the end of the ECT sessions. Her sleep and appetite had improved. She was advised to continue the antipsychotic medication. After one-month of follow-up, her psychotic symptoms were much reduced and she had started helping with household chores and also took care of the children. She was maintained on Olanzapine $5 \mathrm{mg}$ and Sertraline $25 \mathrm{mg}$.

\section{Case 2}

A 29 year old, single, male, graduate who had completed his BA, from a middle socioeconomic status, with no family history of mental illness presented with the complaints of sleep disturbances, social withdrawal, poor self-care and talking to self for a period of three months.

On clinical examination, he had delusions of persecution of someone trying to harm him and delusions of reference that others were watching and talking about him and hostile auditory hallucinations with irregular eating and sleeping patterns. The client had no suicidal ideations or thoughts. The client was diagnosed with first episode psychosis - paranoid schizophrenia. He was treated with Risperidone $4 \mathrm{mg}$.

After two weeks of treatment, the client presented with catatonic symptoms such as poor psychomotor activity, mutism, negativism and poor self-care. $\mathrm{He}$ was administered ECT for catatonia. The preliminary ECT was given at $90 \mathrm{mc}$, and the client attained a delayed seizure for a duration of 40 seconds. He was administered 4 ECT sessions on alternate days. Significant improvement was seen in the client post ECT with reduction in the catatonic symptoms. Feeding and selfcare resumed gradually. The client was on maintenance dose of Olanzapine $10 \mathrm{mg}$ and Lorazepam $2 \mathrm{mg}$ in divided doses.

\section{Case 3}

19-year-old, single, female, who had completed 12th std., from a middle socio- economic status with a family history of delusional disorder in mother, presented to the psychiatric OPD with complaints of not talking, not eating and not reacting. The client had been exhibiting these symptoms since one week.

On clinical examination, she was found to be conscious but uncooperative, unkempt and with poor eye contact and occasional agitation. Mutism was present. A provisional diagnosis of catatonia was made.

The client was started on lorazepam 4 mg inj., IV stat and IM 4 mg/day. There was little clinical improvement with lorazepam treatment and she continued to have catatonic symptoms like mute affect, retarded psychomotor activity, stupor, and decreased blink rate. Hence, ECT was advised.

A total of 8 ECT sessions were administered with an average of 150 $\mathrm{mc}$ leading to adequate seizure in all the sessions. Client showed marked improvement after the ECT sessions. Feeding and communication improved immediately with gradual improvement in other psychopathology such as psychomotor retardation. With further history, a diagnosis of depression with psychotic symptoms was made and managed accordingly with antipsychotics and antidepressants. 
The objective of this case series is to highlight the usefulness and safety of early use of ECT for individuals with first episode psychosis for various indications and its effectiveness in reducing the symptom severity within a short period of time.

All the subjects in this case series received modified bilateral ECT. The number of sessions of ECT varied according to the indications and symptom reduction during the course of the ECTs. The efficacy of the treatment was assessed clinically before and after the session and after one week post-ECT. The subjects showed marked improvement in their psychopathology and functioning at the end of the ECT sessions and these effects were sustained at one month follow-up period. No adverse effects were observed during or immediately after ECT and at follow-up period.

Similar findings were observed in other studies that have shown ECT as a safe and effective form of treatment for young adults with intractable first episode schizophrenia. In these studies, patients showed that ECT had significant higher cumulative response rate, thus making it a valuable treatment option. ${ }^{19,20}$ Furthermore a few studies have also shown a positive outcome of treatment for combined effect of ECT and antipsychotic drug treatment. $^{15,21,22}$ Similarly, studies have shown that women with postpartum psychosis respond better to ECT with almost complete remission in their mood and psychotic symptoms. $^{23,24}$ Patients also show a reduction in their suicidal ideations after ECT treatment.

It is clear that fatality rates from catatonia significantly decreased after the introduction and adoption of ECT as standard treatment in psychiatry.
Hypothesizing the existence of different forms of catatonia, ECT would be more effective in "top-down" than in "bottom-up" variants of the syndrome. ${ }^{25}$ Few researchers believe that ECT should be preferred to benzodiazepines as their effect on catatonic symptoms can be only transient and not every sign/symptom of an acute catatonic stupor responds well to benzodiazepines. Moreover, the efficacy of ECT for catatonia is found to be $80-100 \%$ with good symptom remission. ${ }^{26}$

From the various studies, it can be seen that ECT is a highly effective and faster from of treatment, where pharmaco-therapy seems to have failed or symptoms are acute and unmanageable. In cases that present with severe psychotic symptoms and high risk of suicide, ECT could be considered as the first line of treatment as the remission rate associated with ECT is found to be higher and faster than that of many forms of pharmacotherapy. Intensive ECT relieves the high rates of mortality associated with malignant catatonia and delirious mania. In addition, when depression, mania, and psychotic symptoms accompany systemic illnesses or are present during early pregnancy or the postpartum breastfeeding period, the administration of medications is often precluded, and ECT becomes a useful treatment option. From this, it is evident that electroconvulsive therapy seems to be a better treatment option not only for patients who have poor treatment resistance but also for faster symptom resolution and with drug side effects.

However, long duration and a chronic course of psychiatric disorders are negative outcome variables predicting higher risks for treatment resistance against both medication and ECT. ${ }^{27}$ 
Moreover, the primary use of ECT is affected by severe stigma, and legal restrictions against its mode of use.

\section{Conclusion}

This case series provides preliminary results towards the usefulness of considering ECT as a primary treatment option for individuals with first episode psychosis who present with acute and severe "psychiatric symptoms such as catatonia, suicidality and treatment resistance early in the course of illness. More research in the future should be directed to not only at the use of ECT as a first line of treatment during acute situations but also as maintenance therapy and in long term use.

\section{Conflict of interest}

Nil

\section{Funding source}

Nil

\section{Acknowledgements}

We like to thank Ms. Greeshma Mohan and Ms. Karpagavalli for helping us with data retrieval on ECT. This work was supported by India-US Fogarty Training in Chronic NonCommunicable Disorders \& Diseases Across Lifespan Grant \# 1D43TW009120 (Raghavan, Fellow; LB Cottler, PI).

\section{References}

1. Kane JM, Rifkin A, Quitkin F, Nayak D, Ramos-Lorenzi J. Fluphenazine vs placebo in patients with remitted, acute firstepisode schizophrenia. Arch Gen Psychiatry. 1982;39(1):70-73.
2. Flaum MA, Andreasen NC, Arndt S. The lowa prospective longitudinal study of recent-onset psychoses. Schizophr Bull. 1992;18(3):481-490.

3. McGorry PD, Edwards J, Mihalopoulos C, Harrigan SM, Jackson HJ. EPPIC: an evolving system of early detection and optimal management. Schizophr Bull. 1996;22(2):305-326.

4. Morgan C, Dazzan P, Morgan K, Jones $P$, Harrison $G$, Leff $J$, et al. First episode psychosis and ethnicity: initial findings from the AESOP study. World Psychiatry. 2006;5(1):40.

5. Breitborde NJK, Srihari VH, Woods SW. Review of the operational definition for first-episode psychosis. Early Interv Psychiatry. 2009 Nov;3(4):259-65.

6. McCann TV, Lubman DI, Clark E. First-time primary caregivers' experience of caring for young adults with first-episode psychosis. Schizophr Bull. 2011 Mar;37(2):381-8.

7. O'Donoghue B, Lyne J, Madigan K, Lane A, Turner N, O'Callaghan E, et al. Environmental factors and the age at onset in first episode psychosis. Schizophr Res. 2015 Oct;168(1-2):106-12.

8. Iyer $S N$, Mangala $R$, Thara $R$, Malla AK. Preliminary findings from a study of first-episode psychosis in Montreal, Canada and Chennai, India: comparison of outcomes. Schizophr Res. 2010 Aug;121(13):227-33.

9. Power P. Outcome and recovery in first-episode psychosis. $\mathrm{Br} J$ 
Psychiatry J Ment Sci. 2017 Dec;211(6):331-3.

10. Demjaha A, Lappin JM, Stahl D, Patel MX, MacCabe JH, Howes $\mathrm{OD}$, et al. Antipsychotic treatment resistance in first-episode psychosis: prevalence, subtypes and predictors. Psychol Med. 2017 Aug;47(11):1981-9.

11. Kanahara N, Yamanaka H, Suzuki T, Takase M, lyo M. First-episode psychosis in treatment-resistant schizophrenia: a cross-sectional study of a long-term follow-up cohort. BMC Psychiatry [Internet]. 2018 Sep 3 [cited 2018 Dec 3];18. Available from: https://www.ncbi.nlm.nih.gov/pmc/a rticles/PMC6122618/

12. Zervas IM, Theleritis C, Soldatos CR. Using ECT in schizophrenia: a review from a clinical perspective. World J Biol Psychiatry Off J World Fed Soc Biol Psychiatry. 2012 Feb;13(2):96-105.

13. Sanghani SN, Petrides G, Kellner $\mathrm{CH}$. Electroconvulsive therapy (ECT) in schizophrenia: a review of recent literature. CurrOpin Psychiatry. 2018 May;31(3):21322.

14. Read J, Bentall R. The effectiveness of electroconvulsive therapy: a literature review. Epidemiol PsichiatrSoc [Internet]. 2010 [cited 2017 Apr 22];19(04):333-347. Available from:

http://journals.cambridge.org/abstr act_S1121189X00000671

15. Ahmed S, Khan AM, Mekala HM, Venigalla $\mathrm{H}$, Ahmed $\mathrm{R}$, Etman $\mathrm{A}$, et al. Combined use of electroconvulsive therapy and antipsychotics (both clozapine and non-clozapine) in treatment resistant schizophrenia: A comparative meta-analysis. Heliyon. 2017;3(11):e00429.

16. Lima NN, Nascimento VB, Peixoto JA, Moreira MM, Neto ML, Almeida $\mathrm{JC}$, et al. Electroconvulsive therapy use in adolescents: a systematic review. Ann Gen Psychiatry. 2013;12(1):17.

17. Adhikari SR. Electroconvulsive Therapy in First Episode Schizophrenia-Experiences from Nepal. J PsychiatrAssoc Nepal [Internet]. 2014 [cited 2017 Sep 4];3(1):35-40. Available from: http://www.nepjol.info/index.php/JP AN/article/view/11350

18. Üçok A, Çakir S. Electroconvulsive therapy in first-episode schizophrenia. J ECT [Internet]. 2006 [cited 2017 Sep 4];22(1):3842. Available from: http://journals.Iww.com/ectjournal/A bstract/2006/03000/Electroconvulsi ve_Therapy_in_First_Episode.8.as px

19. Zhang Z-J, Chen $Y-C$, Wang H-N, Wang $\mathrm{H}-\mathrm{H}$, Xue $\mathrm{Y}-\mathrm{Y}$, Feng $\mathrm{S}-\mathrm{F}$, et al. Electroconvulsive therapy improves antipsychotic and somnographic responses in adolescents with first-episode psychosis-A case-control study. Schizophr Res. 2012;137(1-3):97103.

20. Suzuki K, Awata S, Takano T, Ebina Y, Takamatsu K, Kajiwara T, et al. Improvement of psychiatric symptoms after electroconvulsive therapy in young adults with intractable first-episode schizophrenia and schizophreniform disorder. Tohoku J Exp Med. 2006 Nov;210(3):21320. 
21. Cusa BV, Klepac N, Jakšic N, Bradaš Z, Božicevic $M$, Palac $N$, et al. The effects of electroconvulsive therapy augmentation of antipsychotic treatment on cognitive functions in patients with treatment-resistant schizophrenia. J ECT. 2018;34(1): 31-34.

22. Ipekcioglu D, Yazar MS, Canbek $\mathrm{O}$, Yuksel O, Meterelliyoz KS, Ilnem MC. Electroconvulsive therapy combined with antipsychotic therapy in the treatment of acute schizophrenia inpatients: symptom profile of the clinical response. Psychiatry ClinPsychopharmacol. 2018;28(4):363-370.

23. Sit D, Rothschild AJ, Wisner KL. A review of postpartum psychosis. J Womens Health. 2006;15(4):352368.

24. Grover S, Sahoo S, Chakrabarti S, Basu D, Singh SM, Avasthi A. ECT in the postpartum period: $A$ retrospective case series from a tertiary health care center in India. Indian $J$ Psychol Med. 2018;40(6):562.

25. Luchini F, Medda P, Mariani MG, Mauri M, Toni C, Perugi G. Electroconvulsive therapy in catatonic patients: Efficacy and predictors of response. World $\mathrm{J}$ Psychiatry. 2015;5(2):182.

26. Sienaert $P$, Dhossche DM, Vancampfort D, De Hert $M$, Gazdag G. A clinical review of the treatment of catatonia. Front Psychiatry. 2014;5:181.

27. Baghai TC, Möller H-J. Electroconvulsive therapy and its different indications. Dialogues Clin Neurosci. 2008;10(1):105 